\title{
Scripta
}

Revista Internacional de Literatura i Cultura Medieval i Moderna

\section{Itàlia i la configuració de la llegenda negra borgiana}

\author{
Italy and the creation of Borgia's black legend
}

\author{
Joan Emili Roig Matoses \\ ginesta76@gmail.com \\ Universitat de València
}

Resum: La llegenda negra dels Borja va començar a Itàlia i la van començar els italians en el segle XV. Començada a forjar per cronistes, informadors, cardenals... i contràriament al que es podria pensar, aquesta no va començar després de la mort del segon papa Borja Alexandre VI, sinó durant el seu cardenalat, el seu pontificat i com no, després de la seua mort i continuant els segles posteriors amb acusacions falses com la simonia, el incest, els assassinats...

Paraules clau: Borja, Roderic de Borja, Alexandre VI, llegenda negra, Bichi, papa, conclave, simonia, Ascanio Sforza.

Abstract: The black legend of Borgia's family began in Italy and Italians began in the fifteenth century. Created by reporters, cardinals... and contrary to what you might think, not this black legend began after the death of the second Pope Alexander VI Borja but the cardinal time, and of his pontificate, after his death and continue over the following centuries with false accusations as simony, the incest, murder...

Keywords: Borja, Roderic de Borja, Pope Alexander VI, black legend, Bichi, Pope conclave, simony, Ascanio Sforza. 
Joan Emili Roig Matoses. Itàlia i la configuració de la llegenda negra borgiana.

\section{Introducció}

Com és ben sabut, la Itàlia de l'edat mitjana estava estructurada i dividida en ciutats-estat i altres territoris que configuraven un mapa polític i cultural únic en l'Europa de l'època. Al nord ens trobàvem amb el ducat de Milà, a l'oest Gènova i a l'est la República de Venècia. El centre italià estava dominat per la república de Florència i els Estats pontificis i finalment, el regne de Nàpols controlava el sud.

Tot i aquest sistema polític complicat, els estats italians van anar mantenint la seua independència els uns dels altres i provocant, alhora, un equilibri de poders que va ser pràcticament inalterable, però amb importants sotracs causats per les potències exteriors- al llarg dels segles. Aquest joc d'estats es va acabar al segle XIX, quan es va entronitzar els Savoia i es va crear el regne d'Itàlia, per tal d'unificar políticament tota la península. I caldria apuntar que, curiosament, aquesta unificació italiana va ser el gran somni polític d'Alexandre VI. Gran part de la seua política «expansionista» $\mathrm{i}$ intervencionista italiana, va anar encaminada a aconseguir aquest objectiu, fent servir, com no podia ser d'altra manera, els seus fills, que va anar casant-los estratègicament per tal de reforçar aliances -seria el cas de Lucrècia o Jofre- o, fent capitanejar els exercitis papals, primer amb el seu fill Joan, i, després, amb molta més fortuna, amb Cèsar.

Malauradament, quan aquest pla polític estava en ple auge i hauria pogut ser culminat amb èxit, Alexandre VI va emmalaltir inesperadament i va morir. Després, la fortuna de Cèsar Borja va canviar radicalment, tot i els intents d'aquest, en un primer moment, de «col locan» en el soli pontifici un papa neutral que li assegurés una continuïtat en el poder. I així, Francesco Todeschini-Piccolomini, un cardenal vell i malalt va ser entronitzat com a Pius III, gràcies a les maniobres de Cèsar entre els cardenals; però, per a dissort del Borja, el seu pontificat va durar només 26 dies. Després, tot i retre obediència al nou papa, la seua caiguda va ser inexorable.

A Pius III el va succeir el gran enemic d'Alexandre VI, Giulano della Rovere, que per fi aconseguia el gran somni de seure a la cadira de Sant Pere, amb el nom de Juli II. Tot i les vanes promeses d'obediència de Cèsar Borja, Juli II li va treure la capitania general dels exèrcits pontificis, annexionà el ducat de la Romanya als Estats vaticans i, fins i tot, el va empresonar.

El papat d'aquesta època, i com el de segles anteriors, dominava, com ja hem dit, la part central d'Itàlia. Un domini que també s'estenia a tota la resta de la península. El poder, la por, els excessos dels màxims representants eclesiàstics eren coneguts per tothom. Les veus crítiques que des de feia segles intentaven reformar l'església no es cansaven de denunciar i difondre tots els aspectes negatius que feien de Roma i els palaus vaticans el centre de la corrupció eclesiàstica.

El Cisma d'occident va fer créixer aquesta mala imatge que tenia l'església des de feia segles, atés que les lluites de poder per fer-se amb la tiara pontifícia per part d'uns i d'altres, les excomunicacions mútues d'un papa a altre per erigir-se en autèntic successor de Sant Pere, l'establiment de la cort papal ara ací, ara allà... 
A tot açò calia afegir les habituals crítiques que la societat i els enemics del papa de torn feien: abusos de poder, simonia, nepotisme, tràfic d'influències, moral relaxada, gran ostentació del poder i de la riquesa... En resum, les crítiques contra els papes i la corrupció generalitzada de l'Església no eren una cosa desconeguda ni poc habitual quan Alfons de Borja i Roderic de Borja van accedir al soli pontifici.

De la mateixa manera que van actuar Calixt III i Alexandre VI, ho van fer tant els papes anteriors com els posteriors, fins mitjans del segle XVI, quan el Concili de Trento i la Contrareforma van fer canviar aquestos hàbits tan qüestionats i criticats.

Políticament, tots els papes tenien el mateix anhel: convertir el papat en una espècie de monarquia hereditària entre els seus, $i$, per tal d'aconseguir-ho, el nepotisme, el nomenament de cardenals de la família $\mathrm{o}$ afins als seus interessos, la simonia, els assassinats... eren una pràctica habitual entre tots ells, no només entre els Borja.

Significatives i d'una importància especial són les següents paraules de Sanchis Sivera defensant els Borja i la figura d'Alexandre VI:

Ha sido tanto el cieno que se ha arrojado sobre la figura de este personaje, y tan ultrajado por la Historia y expuesto al escarnio de las generaciones de tres siglos, que se tiene como verdad inconcusa el considerarlo como el prototipo de la infamia, la crueldad y la lujuria, y raro es el historiador que no estima por cierto todo lo odioso que de él se ha dicho, sin tomarse el trabajo de estudiar los fundamentos de tales apreciaciones. Y no sólo siguen este procedimiento los autores heterodoxos, sino que hasta los católicos lo emplean con gran daño de la verdad, menosprecio de la crítica y escándalo de los fieles. [...] Se da el peregrino caso de tenerse como verdadero todo la malo que los historiadores, aunque hayan alcanzado fama de poco veraces, dicen contra los Borjas; y se tiene por falso lo que les beneficia y lo que escriben en desdoro de otros Papas; y esto sin examen crítico de ninguna clase, ni razonamiento alguno, y siempre sistemáticamente. Las noticias injuriosas contra Rodrigo de Borja se admiten de ordinario sin pedimento de prueba, como sucede en todo tribunal, sin considerar que no basta un se dice o un se cuenta, ni lo que manifiestan sin examinarlo juiciosa y prudentemente, las memorias, historias secretas, cartas familiares, escritos anónimos [...] pero no será superfluo decir que aquel Rodrigo de Borja que a los veinticinco años de edad había escrito ya libros en defensa de la Santa Sede; que desde que fué nombrado Vicecanciller de la Iglesia demostró gran habilidad y exquisito tacto en cuantos sucesos intervino; que bajo el gobierno de cuatro Pontífices, de los que era verdadero mentor, fué creciendo siempre su influencia y poderío; que fué el ídolo del pueblo romano; que resolvió con grán éxito cuantos asuntos diplomáticos se le encomendaron, no pudo ser en modo alguno el monstruo de la historia novelesca que conocemos, ni es posible fuera como nos lo pintan sus detractores. Si se entrara en comparación con otros Pontífices y Cardenales, por cierto muy alabados por los que maltratan al nuestro, no saldría muy malparado Rodrigo de Borja [...] La mayor parte de los acontecimientos que se relatan en la Historia, si los estudiamos aisladamente son verdaderas monstruosidades muchas veces, pareciéndonos, en cambio, muy racionales y justificados si los miramos en relación con su época [...] En su época, que era muy pagana, fué más clerical que algunos Papas que le antecedieron y siguieron. (Sanchis Sivera 1909: 120-122). 
El vell Alfons de Borja, un valencià arribat a Roma el 1444, en ser-li donat el capell cardenalici de mans del papa Eugeni IV, va dur una vida ordenada i sense estridències al llarg dels 11 anys que va ser titular de l'església dels Quattro Santi Coronati. El nepotisme, tan normal i habitual en aquella època, va fer que el vell Borja portés de València amics, coneguts i familiars.

Un xiquet jovenet i ben plantat, de nom Roderic, venia de València per quedar-s'hi. Aquest, va ser retratat per Girolamo Porcari de la següent forma: «Extat Alexander statura procerus colore medio nigris oculis: Ore paululum pleniote: Valitudie prospera laboris altra fidem patiens seu sol: Seu sit imber Eloquentia preditus singulari a seuitia omni penitus alienus omnium expers quae ad gubernandam rem publicam pertinent» (Porcari 1493: 39).

El nebot del futur Calixt III desembarcava a Itàlia amb 18 anys, junt amb el seu cosí Joan lluís del Milà i Borja, l'any 1449, i per començar els seus estudis i una carrera eclesiàstica que culminaria amb l'assoliment de la tiara papal l'11 d'agost de 1492.

En el present article volem fer un repàs sobre dos dels temes sobre els quals s'ha bastit la famosa i falsa llegenda negra dels Borja, llegenda creada inicialment i promoguda exclusivament per italians a Itàlia. En aquest sentit, analitzarem els dos primers episodis sobre els quals va començar a bastirse aquesta: el famós bateig dels Bichi i el conclave de 1492, en el qual Roderic de Borja va eixir escollit papa.

\section{Els inicis de la llegenda negra.}

La llegenda negra dels Borja no va començar amb el primer papa Borja, sinó amb el segon, i quan aquest encara no era pontífex sinó cardenal. Contràriament al que molts podrien pensar, aquesta no va començar una vegada mort Alexandre VI, sinó que va començar abans del seu pontificat, va consolidar-se durant el mateix i va perviure i augmentar durant els segles posteriors.

La vida privada de Roderic de Borja durant els quatre pontificats (Pius II, Pau II, Sixt IV i Innocenci VIII) que es van esdevenir després del pontificat del seu oncle, Calixt III, és poc coneguda i ben poc se'n sap. Tot i això, ens trobem amb un primer episodi que involucra el Borja en un suposat escàndol sexual, la notícia del qual va córrer per tota Itàlia, ocorregut el juny de 1460.

L'estiu de 1460, un jove cardenal valencià i vicecanceller de 29 anys, junt amb el cardenal d'Estouteville, van assistir a Sena al bateig d'una filla de la prestigiosa família Bichi i, també anaren a la festa posterior, ja que eren els padrins de la xiqueta (Schüller Piroli 1990: 92). Segons molts autors, com la mateixa Schüller Piroli o Gregorovius, «Un dia hi organitzà una bacanal» (Gregorovius 2007: 44). Segons els diferents rumors que van córrer a l'època i que van arribar a oïdes de Pius II, amb el consegüent disgust del mateix, els dos cardenals, una vegada acabat el bateig, es van dirigir al banquet i van participar a la festa privada celebrada en els jardins de la família Bichi. Una vegada entraren els cardenals $i$ totes les dones, aquestos van tancar les portes perquè no pogueren entrarhi els marits d'aquestes i es van deixar abraonar per la luxúria i el desenfrenament durant bastants 
hores, sense que els marits pogueren fer res perquè l'autoritat eclesiàstica podia més que la seua gelosia.

Ràpidament la notícia de la suposada bacanal va córrer i va arribar fins als banys de Petriolo, on es trobava el papa Pius II reposant. Aquest, en data d'11 de juny de 1460, va escriure la següent carta per, teòricament, recriminar amb severitat la libidinosa conducta dels esmentats cardenals:

Pius pp. II. Vicecancellario.

Dilecte fill Salut. etc. Nudius quartus cum in ortis dilecfi filli Johannis de Bichis convenissent femine complures Senenses ad secularem vanitatem composite Audivimus Cir (cumspectionem) tuam parum dignitatis quam sustinet memorem inter illas ab hora fere XVIIa usque ad XXIIam fuisse et ex Collegio tuo socium te habuisse eum quem si non honor apce Sedis etas tamen admonere satis officii sui debebat. Saltatum ibi est at accepimus, cum omni, licentia, nullis iliecibris amatoris parsum. Tuque etiam inter hec omnia non secus versatus quam si unus esses ex secularium juvenum turba. Referre sigilatim omnia pudet que eo in loco facta asseruntur, Ista non modo re sed appellatione quoque indigna sunt gradu quem tenes. Marifi patres fratres et consanguinei puelarum que aderant ut liberior vobis esset voluptandi facultas ab ingressu prohibebantur, vos soli cum paucis domesticis auctores hortatoresque chorearum eratis: Dicitur nulla nunc de re alia esse in Civitate Senensi sermonem preterquam vanitatem tuam ab omnibus irrideri. Hiec certe in balneis ubi ecclesiasticorum et secularium non parvus est numerus vulgi es fabula. Si diceremus ista nobis non displicere erraremus vehementer : displicent certe super quam dici possit. Vituperatur enim ecclesiasticus ordo vituperatur ministerium nostrum, neque ad vite honestatem sed ad occasionem lascivie ditari et magni fieri videmur. Hinc principum et potentatuum in nos surgit contemptus, hinc quottidiane laicorum irrisiones hinc etiam reprehensiones vite nostre cum reprehendere altos volumus, Vicarius quoque Christi qui indulgere talia creditur in eundem cadit contemptum. Valentine ecclesie prees dilecte fili que inter Hispanorum ecclesias precipua est apostolice etiam cancellarie regimen tenes quodque factum tuum reprehensibilius tacit, ad consilium Romane sedis inter Cardinales cum Pontifice sede. Si puellis blandiri fructus missitare hinc inde, vinum pregustatum illi quam diligas mictere, effuso studio onfne genus voluptatis totam diem spectare denique ut fieri omnia licentius possint maritos, necessarios illarum excludere, gradibus tuis convenire videntur, tibi ipsi judicandum relfiquimus. Reprehendimur nos propter te, reprehenditur Calistri felix recordatio avunculi tui quli cumulandls in te honorlbus judicio plurimum errasse videtur. Quod si excusatoionem allegas etatis, non est ea tibi jam etas ut non intelligas quantum onus dignitas tua sustiueat, esse irreprehensibilem cardinalem oportet vite et morum salutare exemplum, cuius persona omnium non solum animis sed oculis debet inservire. Indignamur postmodum atque irascimur si a principibus seculi parum honorificis titulis appellamur, si in possessionibus beneficforum turbamur, si subjicere colla nostra illorum mandato compellimur. Nos ipsi hec vulnera nobis inferimus, et malorum nostrorum materiam damus id agentes ut ecclesie quoque auctoritas in dies evilescat. Cujus rei in hoc seculo vituperium ferimus, et in alio supplicium dignum luemus, cir(cumspectio) igitur tua hiis vanitatibus modum imponat, dignitatem suam recogitet, nec velit inter juvenes et mulierculas amatoris nomen tenere. Si enim hec rursus acciderent cogemur ostendere nobis invitis et dolentibus ea accidisse neque sine rubore tuo esse nostra animadversio posset. Te semper dileximus et tanquam eum in quo gravitatis et modestie specimen vidimus dignum nostra protectione putavimus. Velis ut opinionem hanc et mentem retinere din possimus, quod nil prestare melius poterit quam vite gravioris assumptio. Anni tui qui correctionem ad huc 
Joan Emili Roig Matoses. Itàlia i la configuració de la llegenda negra borgiana.

pollicentur faciunt ut paterne te moneamus ; Alterius etas si hoc pateretur simili caritatis officio non fungeremur. Datum petrioli XI Junii1460» (Baronii 1880, 29: 230-231).

Aquesta carta va ser publicada en diversos llibres i, posteriorment, ha estat traduïda, malintencionadament (Gregorovius 2007: 44), per aconseguir que les paraules de Pius II tingueren un sentit diferent al que nosaltres veiem.

És cert que el papa Piccolomini es mostra contrariat i, en certa forma, enfadat amb els rumors que li han arribat sobre el seu vicecanceller, però en cap moment podem arribar a concloure que ni se'ls creu ni els dóna per bons, ja que, si fos així, el to de la carta hauria estat molt més dur i no hauria donat cap tipus de mostra d'afecte com el que veiem que demostra cap al Borja: «Te semper dileximus et tanquam eum in quo gravitatis et modestie specimen vidimus dignum nostra protectione putavimus» (Baronii 1880, 29: 231) És més, li demana que a partir d'aquell moment siga més discret en els seus actes públics.

Com ja hem dit, molts han recollit aquest episodi i ens han reportat la carta del papa traduïda i no en l'original llatí del Piccolomini. Autors com Gregorovius o Von Pastor han donat per bona aquesta versió i descriuen un Roderic de Borja que s'oblida de la seua alta dignitat eclesiàstica i es lliura a tot tipus de plaers carnals impropis del seu càrrec.

De Roo és el primer historiador que posa en qüestió l'episodi i ens adverteix de les traduccions malintencionades que uns i altres han fet d'algunes paraules de la missiva del pontífex (De Roo 1924, II: 117). Per exemple, la paraula «voluptandi» que Gregorovius tradueix com «delits amorosos» o Von Pastor com «piacere sensuale», si fem una traducció acurada hauríem de dir: 'alegria', 'joia', 'divertiment'...

És evident que l'escàndol derivat de la rumorologia devia inquietar el papa i que aquest, impulsivament, li va escriure una carta, en la qual en cap moment està donant per vàlida la història que li ha arribat, ja que ell mateix diu «es parla», «es comenta», o, «tot el que es diu que es va fer allí em dóna vergonya de detallar» (《referre sigilatim omnia pudet que eo in loco facta asserentur»). Però, volem insistir que el papa no es va creure la història, tot i que sembla que si que li feia mal la mala imatge que donaven a l'església aquestos rumors. Pensem també que, si se’ls hagués cregut, a la carta hauria anunciat algun tipus de càstig sever per als dos cardenals instigadors i participants en una orgia.

La història devia circular ràpidament per Sena i per tota Itàlia, gràcies a cartes com la següent, que Bartolomeo Bonatto va escriure el 8 de juny de 1460 a Bàrbera de Brandemburg:

Non ho altro da scrivire a Vostra Signoria, se non che oggi qui c'è stato il battesimo della figlia di un signore di Siena, e che a questo battesimo presero parte como padrini il cardinale di Roano e il'Vicecancelliere. Le loro Eminenze non compariono in chiesa, ma fecero tenere a 


\begin{abstract}
battesimo la bambina da loro procuratori, mentre invece intervennero alla festa che si svolse on un giardino di propietà di questo signore. Lì fiu portata la loro figlioccia, lì la videro, e lì convenne tutto quello che c'è di meglio in Siena. È stata una bella festa ma non c'è intrato persona che non porti chiera, mi perdoni quindi se non posso dare maggiori particolari, ma non ero fra gli invitati.Un senese, uomo piacevole, dopo aver cercato vanamente tutto in giro al giardino il modo de penetrari, disse: -Se il bambini che nascerano entro uno anno dovessere venire al mondo con gli stessi abiti che portano il loro padri, dovrebbero tutti comparire vestiti da preti o da cardinali (Luzio 1914: 471).
\end{abstract}

La frase burlesca i sarcàstica del final, per cert, és inigualable. El retrat que es dóna, dels dos cardenals que són padrins d'un bateig, però, que no van a la cerimònia religiosa i que munten en uns jardins una orgia amb les dones dels marits als quals han deixat fora, és impagable. I, també, al nostre parer, bastant increible. Sobretot, quan el relat dels fets ve d'una persona que no estava convidada a la festa, com ell reconeix, i és per això que no li pot donar grans detalls de la mateixa. Tot i que si que li transmet el que es diu i es comenta que va passar, i, sobretot, quines seran les conseqüències de la festa en un any.

Tal i com Bonatto escriu a la carta, en un any haurien de nàixer molts nens a Sena, fruit d'aquella bacanal, els pares dels quals haurien estat els dos cardenals romans. Si això hagués passat, estem convençuts que hauríem trobat testimonis escrits a dietaris, epistolaris, cròniques... Però no hem trobat res, i això ja és un primer punt a favor per no creure'ns la història.

Si fem servir el mateix to irònic de la carta per descriure els fets, podríem fer una reconstrucció de la festa de la següent manera: Els dos cardenals acudeixen a un bateig al qual van els hòmens i dones més importants de Sena. Acabat aquest, el Borja i el company se'n van corrents als jardins de la família Bichi, on es realitzarà la festa per esperar els convidats. Quan aquests hi arriben, no sabem si uns criats dels cardenals o ells mateixos diuen qui ha d'entrar i qui no: és a dir, obliguen a les dones a entrar $\mathrm{i}$ als hòmens a quedar-se fora. Llavors tanquen les portes i comença la bacanal, l'orgia i la festa, en la qual les dones accepten voluntàriament i gustosa de participar, mentre els seus marits, per devoció a la santa mare Església, i per respecte a les altes dignitats que els dos cardenals representen, han deixat que les seues dones entren soles, sense cap mena d'oposició ni contrarietat. I mentre, des de fora, deuen escoltar els crits de plaer dels participants a l'orgia, i ells, pacientment i resignada, es passegen pel jardí, sota el sol del mes de juny, durant cinc hores. Finalment, acabada la festa, se'n tornen tots a casa, com si no hagués passat res. És creible aquest relat? Doncs és tan creible com la carta que acabem de transcriure...

Aquest bateig i la posterior festa no va ser organitzada pel Borja i és més que probable que aquesta fos feta per a un nombre reduït de gent; i, segurament, només per a membres de la família Bichi, que devien voler fer, d'aquesta, una festa familiar, i no multitudinària (La Torre 1935: 15). Evidentment que els pares, marits, germans i altres familiars de sexe masculí van participar a la festa perquè, altrament, l'exclusió d'aquestos hauria comportat problemes amb el Borja i el seu company, per molt cardenals de l'Església romana hagueren estat. 
Joan Emili Roig Matoses. Itàlia i la configuració de la llegenda negra borgiana.

Lamentablement, la carta de resposta al papa que Roderic de Borja va escriure no s'ha localitzat encara i, no coneixem quina va ser la versió que ell va donar, dels fets ocorreguts; però sí que tenim la valuosa resposta que el papa va fer a aquesta:

\footnotetext{
Pius pp. II Vicecancellario

Dilecte fili etc. Accepimus literas tue cir(cumspectio) nis et intelleximus excusationem quam affers. Factum tuum Dilecte fili non potest nin culpabile esse, licet minus fortasse sit quam fuerit nobis relatum. Hortamur ut a talibus deinceps bastineas honorique tuo prudencis consulas. Ignoscimus tibi veniam a nobis petenti, nec si te non dilexissemus ut filium nostrum peculiarem non ita amanter monuissemus: Scriptum est enim: Ego quos amo arguo et castigo. Quamdiu bene feceris et modeste vixeris non deerit pater protectorque bonus tibi ac tuis, vitamque avunculi tui predecessoris nostri, Pio vio, non multum desiderare habebis. Datum etc. XIIII Junii.» (De Roo 1924, 11: 433)
}

La diferència del to de la primera carta respecte a aquesta és més que evident. Passem d'un papa preocupat, escandalitzat pels rumors que corren sobre el Borja, per a major vergonya de l'Església, a un papa que accepta les seues excuses i al legacions, les entén i finalment, l'exculpa de totes les maledicències que li havien arribat. Tot i això, li demana que, a partir d'aquell moment, siga més prudent. I conclou la carta dient-li que el compensarà per la injustícia comesa. De fet, el mateix De Roo enumera i documenta tots els beneficis que Roderic de Borja va rebre de mans de Pius II: El 21 de setembre de 1460 l'administració del monestir cistercenc de Santa Maria de la Roca a la diòcesi de Tarragona; el 23 d'abril de 1461 la del monestir benedictí de Ripoll; el 4 de juliol del mateix any li va confirmar al Borja les rendes de la diocesi de Pamplona; el 1462 es nomenant bisbe de Cartagena; el 1463 rep la diòcesi de Mallorca i el 14 d'abril de 1463 la de Tortosa (De Roo 1924, 11: $127-136)$

Seguint els consells del Piccolomini, Roderic de Borja va viure sense provocar cap escàndol. De fet, de la seua vida privada, fins l'any 1492, ben poc se'n sap.

\section{L'ascens d'Alexandre VI al la càtedra de Sant Pere.}

L'11 d'agost de 1492, Roderic de Borja assolia el lloc més alt al qual un eclesiàstic pot arribar, la cadira de Sant Pere. Les acusacions de simonia per aconseguir la tira pontifícia van circular ràpidament, només obrir-se les portes del conclave i ser proclamat papa Alexandre VI. Segons els rumors que van córrer per Roma, Roderic de Borja havia comprat els vots d'alguns dels cardenals; fet que intentarem demostrar com a fals i com a un rumor més dels que van ajudar a créixer i augmentar la llegenda negra borgiana.

La nòmina d'autors que es van apuntar a desprestigiar aquesta elecció, marcant-la amb l'estigma

SCRIPTA, Revista internacional de literatura i cultura medieval i moderna, núm. 5 / juny 2015 / pp. 207-228 ISSN: 2340-4841 · doi:10.7203/SCRIPTA.5.6382 
de la simonia, és àmplia. Destaquen, per damunt de tots aquestos noms: Jacopo Sannazzaro i Francesco Guicciardini.

Sannazzaro és autor del següent epigrama, ben conegut, que ens ofereix la imatge d'un Alexandre VI que ho va vendre tot per tal d'aconseguir el papat: «Vendit Alexander claves, altaria, Christum. / Emerat ille prius, vendere iure potest.» (Bower 1776, 7: 369).

Per altra banda, Guicciardini és l'autor que més malament ha tractat els Borja i, especialment, la figura d'Alexandre VI, al qual posa de paradigma dels següents oprobis: viciós, luxuriós, sodomita, que practicava l'incest amb la seua filla, assassí de cardenals amb el famós verí borgià i també, d'aconseguir amb arts perverses i simonia la tiara.

En les seues Storie fiorentine, obra escrita després de la mort Alexandre VI, diu, sobre l'elecció d'aquest, en el conclave de 1492:

\begin{abstract}
Ne l'anno medesimo e del mese di..., morí papa Innocenzio ed in suo luogo fu eletto Roderigo Borgia valenziano, vicecancelliere, nipote di papa Calisto, el quale salí in questo grado con favore del signore Lodovico e di monsignore Ascanio, che in remunerazione fu creato vicecancelliere; ma principalmente per simonia, perché con danari, con ufici, con benefíci, con promesse e con tutte le forze e facultà sua si pattuí e comperò le voce de' cardinali e del collegio; cosa bruttissima e abominabile, e principio convenientissimo a' suoi futuri tristi processi e portamenti (Guicciardini 1970: 199).
\end{abstract}

El mateix Guicciardini escriuria, a la seua Storia d'Italia, una descripció ben semblant del caràcter simoníac del conclave. En aquest cas, l'autor encara titlla de més greu el desenvolupament d'aquest:

\begin{abstract}
A Innocenzio succedette Roderigo Borgia, di patria valenziano, una delle città regie di Spagna, antico cardinale, e de' maggiori della corte di Ro-ma, ma assunto al pontificato per le discordie che erano tra i cardinali Ascanio Sforza e Giuliano di san Piero a Vincola, ma molto più perché, con esempio nuovo in quella età, comperò palesemente, parte con danari paste con promesse degli uffici e benefici suoi, che erano am-plissimi, molti voti di cardinali: i quali, disprezzatori dell'evangelico ammaestramento, non si vergognorono di vendere la facoltà di trafficare col nome della autorità celeste i sacri tesori, nella più eccelsa parte del tempio. Indusse a contrattazione tanto abominevole molti di loro il cardinale Ascanio, ma non già più con le persuasio-ni e co' prieghi che con lo esempio; perché corrotto dall'appetito infinito delle ricchezze, pattuí da lui per sé, per prezzo di tanta sceleratezza, la vicecancelleria, uffcio principale della corte romana, chiese, castella e il palagio suo di Roma, pieno di mobili di grandissima valuta. Ma non fuggi, per ciò, né poi il giudicio divino né allora l'infamia e odio giusto degli uomini, ripieni per questa elezione di spavento e di orrore, per essere stata celebrata con arti si brutte; e non meno perché la natura e le condizioni della persona eletta erano conosciute in gran paste da molti: e, tra gli altri, è manifesto che il re di Napoli, benché in publico il dolore conceputo dissi-mulasse, significò alla reina sua moglie con lacrime, dalle quali era solito astenersi eziandio nella morte de' figliuoli, essere creato uno pontefice che sarebbe perniciosissimo a Italia e a tutta la republica cristiana: pronostico veramente non
\end{abstract}


indegno della prudenza di Ferdinando. Perché in Alessandro sesto (cosí volle essere chiamato il nuovo pontefice) fu solerzia e sagacia singolare, consiglio eccellente, efficacia a persuadere maravigliosa, e a tutte le faccende gravi sollecitudine e destrezza incredibile; ma erano queste virtú avanzate di grande intervallo da' vizi: costumi oscenissimi, non sincerità non vergogna non verità non fede non religione, avarizia insaziabile, ambizione immoderata, crudeltà pili che barbara e ardentissima cupidità di esaltare in qualunque modo i figliuoli i quali erano molti; e tra questi qualcuno, acciocché a eseguire i provi consigli non mancassino pravi instrumenti, non meno detestabile in parte alcuna del padre (Guicciardini 1971: 7-8).

En el conclave de 1492 hi havia dos bàndols clarament oposats per tal d'aconseguir la tirara pontifícia. Per una banda estava el partit encapçalat per Ascanio Sforza, germà de Ludovico Sforza «il Moro» i, per un altre costat, el partit de Giuliano Della Rovere, fiduciari de rei de Nàpols. Cadascú d'ells no anava a lluitar per aconseguir el papat per a ells mateixos, sinó per posar una persona fàcilment dominable que servís als seus interessos personals (La Torre 1933: 22).

Contràriament al que molts historiadors han escrit, opinem igual que La Torre: ni l'Sforza ni el Della Rovere van pensar mai a aconseguir realment la tiara i per això van voler «col locar» com a papa una titella. I per què? Ens basem en un argument tan simple com l'edat; el 1492, Ascanio Sforza tenia 37 anys i Giuliano Della Rovere, 49. Ambdós eren dos candidats massa joves per aspirar al papat.

Tots dos partits van arribar al conclave de $1492 \mathrm{amb}$ unes instruccions molt clares: imposar el seu candidat. «Il Moro» li escriu al seu germà una carta, en data de 28 de juliol, en què li diu que «non badare a spese» -que no reparés en despeses-, per tal de véncer la partida, ja que el resultat final a favor d'ells podia reportar-los grans beneficis (Picotti 1921: 106). Per altra banda, el partit de Della Rovere rebia del rei Ferran de Nàpols la suma de 200.000 ducats per tal de poder actuar de la manera que ell considerés, fins i tot emprant la violència, si calia. (La Torre 1933: 28).

És en aquest punt que volem fer notar una xicoteta contradicció que faria trontollar una mica la teoria que Roderic de Borja va comprar la tiara pontifícia amb totes les seues riqueses, palaus, càrrecs... Per un costat trobem documentades les grans quantitats de diners que tenien, tant Ascanio com Giuliano, per comprar els vots dels cardenals i imposar el seu candidat i, per un altre, la suposada facilitat amb la qual Roderic de Borja va poder comprar tot el col legi cardenalici, que li va donar el seu vot en el quart i darrer escrutini. La contradicció és més que significativa i evident. Per tant, alguna cosa més va passar en aquell mes d'agost de 1492.

Gràcies als tres llistats d'escrutini que es conserven d'aquell conclave podem veure com van anar distribuint-se els vots entre els cardenals, quins van ser els favorits en cada votació i qui votava a qui (Schweitzer 1909: 809-814). Després de tres escrutinis, cap dels cardenals dels bàndols Sforza i Della Rovere va obtenir els vots necessaris per ser nomenat papa. Quan semblava que en el quart escrutini es tornaria al punt mort dels tres anteriors, un fet sorprenent es va donar: Roderic de Borja rebia els vots de tots els cardenals. Malauradament, el quart i darrer escrutini no es conserva, 
però, és gràcies a la carta que l'ambaixador florentí Filippo Valori va escriure des de Roma, el 12 d'agost, que sabem el resultat del mateix:

\begin{abstract}
Magnifici Domini mei observandissimi etc..
Per la staffetta di hiermattina la Signorie Ve haranno inteso come fu publicato il Gardinale Vicecancelliere in Sommo Pontefice, Alexandro VIto nuncupato, el quale, doppo una lungha contentione, fu creato omnium consensu, ne li mancò un solo voto. II modo Che si sia tenuto in questa electione le Sigie la intenderanno da Ser Nicholo Michelozi che fra pochi dì parlira di quà, che per buono rispecto non e bone scriverlo, et ancora molti particulari non si possono così bene dire per lettere come a bocha (Burckard 1883, 11: 610).
\end{abstract}

La primera ombra de simonia ja plana en el primer paràgraf de la carta, quan l'autor diu que per respecte és millor no escriure per carta el que ha passat en aquest conclave. Per ara, cap acusació concreta cap al Borja. Això sí: més endavant, anuncia i deixa ben clar -i és la primera vegada que es diu- que Ascanio Sforza és qui ha fet possible l'elecció del nou papa i que li costa d'entendre el per què ho ha fet: «Questa promotione è venuta fuori dell'expectatione di ogni persona, et monsign. Aschanio è stato quello che solo ha facto venire con arte non pichola il Pontificato in costui. Quello che habbi inducto Aschanio non posso anchora intendere» (Burckard 1883, II: 610).

En la resta de carta -i en les posteriors del 14, 16 i 18 d'agost-, Valori confirma el paper decisiu d'Ascanio en el conclave, així com també detalla tots els beneficis, possessions, càrrecs, etc., del Borja a mans de quins cardenals han anat a parar. En cap moment Valori acusa de simonia el Borja directament: simplement, fa planar l'ombra de la simonia per sobre de les seues cartes:

Sua Signoria ha havuto I'offitio della Canclleria et la casa con ogni supellectile del Vicecancelliere: ha havuto el Castello di Nepi et la chiesa di Accia (sic) in Ungheria che rende X mila ducalti l'anno, et molte altre cose. Al Cardinale Orsino e state dato la Rocco Soriana et Monticelli, la legatione della Marcha et la chiesa di Cartagena in Spagna che rende V mila ducati l'anno. Al Cardinal Colonna è slalo dato la Badia di Subdiaco con 20 terre che ronde III mila ducati, o meglio, l'anno; della quale Badia et terre il Papa ne fa padroni la Casa Colonna in perpetuo. Et appresso monsigr. Ascanio ha risegnato il veschovado di Pavia in decto Cardinale Colonna. Al Cardinale SaveIlo s'è dato Civita Castellana et qualeche allra cosa. Al Cardinale S. Giorgio s'è dato benfictii in Spagna per IIII mila ducati, et la casa dove è Stato Ascanio si rende a stanza sua a flgliuoli del Conte Girolamo. II Cardinale San Severino ha havuto la casa del Cardinale che fa di Milano, con qualche altra cosa; el a stanza sua il Papa ha dato intentione all Sigr Fracassa di condurlo con solde di XV mila ducati l'anno: et oltre alle cose predecte, che erano tucte del vicecancelliere, ha dati molti Benefictii et offerti di suoi familiari ad altri familiari di Cardinali, come loro medesimi hanno voluto. Sono stalli molti Cardinali che ne' hanno havuto, ne' voluto cosa alchuna (Burckard 1883, II: 610-611).

SCRIPTA, Revista internacional de literatura i cultura medieval i moderna, núm. 5 / juny 2015 / pp. 207-228 ISSN: 2340-4841 · doi:10.7203/SCRIPTA.5.6382 
Pel fet que Roderic de Borja, essent papa, repartira tots els seus beneficis, possessions i càrrecs, ¿és prou motiu per acusar-lo d'haver-ho fet com a pagament per haver rebut els vots de tots aquells cardenals que apareixen en aquesta nòmina? Segons la llegenda negra, sí; segons molts testimonis contemporanis, també. Segons nosaltres, no és un fet suficient per acusar-lo, com intentarem demostrar.

Si suposadament va rebre els vots de tots els cardenals en el darrer escrutini, ¿iper què hi va haver cardenals que no van voler cap cosa del Borja, tal i com ens relata Valori? Si havien signat un pacte de compra venda, ¿per què no van voler res de res? ¿Per què van esperar a la quarta votació per donar-li unànimement el seu vot? Simplement i senzilla, perquè, segurament, no hi va haver cap pacte al respecte, entre el Borja i la resta de cardenals, per assegurar-se el seu vot.

És ben significativa la carta del 4 d'agost de 1492 que el bisbe de Mòdena, Gianandrea Bocaccio, escriu a la duquesa de Ferrara, i on ens ofereixen unes reveladores paraules sobre Ascanio Sforza i els rumors sobre les seues maniobres i les promeses donades:

\begin{abstract}
Illustrissima Madama mia... A questo pontificato molti concorrono et per lo primo Aleria per la parte de Accanio, et certamente etiam per luniuersale et omnium desiderio per la summa bonta soa item Neapolitanus abenche il Re li obsta molto, nisi sit fictio ad aio che qual' chuno declina in lui per indignatione concetta contra sua Maesta che voglia dare lege in electione suprema ; quando pur se intenda esser il vero chel Re non voglia Napoli, molti che haveuano drizate il pensiero in altri lo convertirano in lui ; quid dicam nescio, vulgo et sripto dicitur chel homo è una mala bestia. Heri publice se disse che' Ascanio se voleva fare papa com pregare ciascuno scorsalo che li volessero dare la voce id est domi la prima, et il signore Ludouico hauere scritto per Tottavilla al castellano de Sanato Angelo non grandissime promissione de capello rosso et altre buone conditione, che volesse fare del castello la volunta del dicio Ascanio; plena est tota civitas et Romana curia hoc rumore seu fama, non se crede pero per li gravi, tutavia non se discrede» (Von Pastor 1910, V: 533).
\end{abstract}

No podem deixar escapar, tampoc, els comentaris de Roderic de Borja com a aspirant a la tiara:

Il vicecancellero segui per potentia de partidi, il può contentare la brigata de molte digne cose: primo colo la cancellarla, ch'è uno alto papato, la temporalita chel ha de doe cita videlicet cita Castellana et Nepe com rocha Suriana, ch'è una aquila fra le terre de la chiesi; una abbatia a l'Aquilla, de valuta de 1000 ducati, ad Albana appressa a Roma una altra simile, in nel Reame due magiore, il veschovato de Porto 1200, l'abbatia de Sublacho pur in le porte de Roma com 22 castelli de valuta de 2000. In Spagna sine fine dicentes XVI veschovati dignissimi et optimi li ha senza le abbatie et molti altri boni et degni beneficiji; primo li ha il veschovato de Valenza de valuta de XVIm ducati, quello de Cartagina VIIm, quello de Maiorcha VIm, labbatia de Valdina appressa a Valenza com molti et molti vassalli 2000 (Von Pastor 1910, V: 533-534). 
Joan Emili Roig Matoses. Itàlia i la configuració de la llegenda negra borgiana.

Molts beneficis podia oferir el Borja als cardenals, però no s'acostava ni de lluny als 200.000 ducats donats al Della Rovere o el «non badare a spese» del Moro, a Ascanio, just abans de començar el conclave...

Tanmateix, una altra història va començar a córrer per Itàlia, aquells dies, que vindria a demostrar la suposada compra, per part del Borja, del vot d'Ascanio. Es tracta de l'episodi de les quatre someres carregades d'argent que el Borja va enviar a casa d'Ascanio, abans de començar el conclave. La història ens ha arribat reportada per Stefano Infessura, en el seu diari:

\footnotetext{
Fertur etiam antequam intrarent conclave predictum vice-cancellarium pro habendo voto Ascanii predicti et sequentium misisse quatuor mulos oneratos argento ad domum dicti Ascanii sub hoc nomine, ut in eius domo custodirentur dum esset in conclave, ect quod securius ibi poterant permanere quam in eius domo; quod argentum fertur fuisse datum dicto Ascanio pro habendo eius voto; civibusque romanis multa proonsit (Infessura 1890: 282).
}

Aquesta història va tenir molt d'èxit, ja que venia a ser la constatació definitiva de les sospites del tracte segellat entre Roderic i Ascanio. Fins i tot quan s'ha traduït el text llatí d'Infessura a altres llengües, l'argent miraculosament s'ha ennoblit i ha acabat convertint-se en or. Un d'aquestos exemples el podem veure en les següents paraules d'Oreste Tommasini: «Epigrammi, diari, tradizioni storiche ci attestano che Roderico Borgia mandò le sue mule cariche d'oro alle case di Ascanio Sforza» (Tommasini 1883: 109).

És molt significatiu que els informadors romans -com Valori-, que escriuen tot tipus de rumors i notícies, curiosament no reporten aquest episodi d'Infessura, que s'ha volgut convertir en la prova definitiva de la simonia d'Alexandre VI. Nosaltres creiem que, si realment -i tenim seriosos dubtes de la seua veracitat, pel fet que ja hem apuntat: ni Valori ni cap altre l'han reflectit i això és molt estrany- va passar aquesta passejada de someres carregades d'objectes de valor -i no d'or-, d'un palau a un altre, tindria una explicació raonable i senzilla.

De la mateixa forma que quan moria un papa es produïen tota una sèrie de tumults i saquejos en les cases dels servidors del papa i, fins i tot, en les estances del papa, mentre aquell encara es trobava de cos present -i és així com va ocórrer, amb la mort d'Alexandre VI que els apartaments Borja van ser saquejats (Burckard 2004: 459)-, de la mateixa forma diem, els mateixos tumults i saquejos es produïen quan un cardenal era elegit papa i la seua casa era saquejada.

És per això que creiem que, si les someres es van passejar realment per Roma, des del palau del Borja fins al palau d'Ascanio, va ser perquè Roderic era ben conscient que entrava en la nòmina de possibles papables i l'Sforza no, com ja hem apuntat més amunt, a causa de la seua edat, i les suposades riqueses que hi va traslladar anaven a estar més segures al palau d'Ascanio que al seu.

Aquesta hipòtesi ens la demostra un fet ocorregut durant el conclave de 1484. Just abans del seu

SCRIPTA, Revista internacional de literatura i cultura medieval i moderna, núm. 5 / juny 2015 / pp. 207-228 ISSN: 2340-4841 · doi:10.7203/SCRIPTA.5.6382 
Joan Emili Roig Matoses. Itàlia i la configuració de la llegenda negra borgiana.

inici, Roderic de Borja devia pensar que tenia serioses possibilitats d'ésser triat papa, per la qual cosa va fer protegir l'entrada del seu palau, per defensar-lo de possibles intents de saqueig, com demostra aquest fragment de la carta de Luigi Andrea Loeti a Lorenzo de Medici, en data 30 d'agost de 1484: «Il Vicecancelliere non si fa mentione ne havessi: et pure, credendosi essere Papa, haveva facto fare due Bastie alle porte della Casa sua per difenderla del sacco se fussi stato Papa» (Burckard 1883, I: 519).

En conclusió, si aquest episodi va arribar a passar, no va ser per subornar Ascanio Sforza i aconseguir el seu vot, sinó perquè per la mateixa raó que el 1484 va témer per casa seua i la va protegir. El 1492 també devia témer per les seues possessions més valuoses i les va fer traslladar a casa del seu amic.

Tornant al conclave de 1484, dies abans del seu inici, les acusacions de corrupció cap al Borja van aparéixer per primer cop, des que hi participava com a cardenal en una elecció. L'orador florentí Vespucci, en una carta a Lorenzo de Medici, datada el 18 d'agost, dóna compte del següent:

\footnotetext{
Scrissivi della praticha teneva Manello; dipoi se né levato, et voleasi al Vicecancelliere, cercha di corrompere il mondo, chi con denari, chi con uficii et chi con beneficii. So che a Ragona, ha fatto proferire l'officio er la chasa, et a Colonna venticinquemila ducati et la Baida di Subiaco ; et el simile al Savello.» (Burckard 1883, I: 503).
}

I en una altra carta datada el 21 d'agost, torna a insistir, amb les mateixes acusacions de simonia: «El vicecancelliere fa grande forza per se con prometter danari, uficcii, la casa sua, beneficii, ma è tenuto su superbo et di mala fede che non se ha paura» (Burckard 1883, I: 507).

¿Què va passar realment en aquell conclave de 1492? Tres escrutinis que no van decidir res i un quart en el qual es va proclamar un papa per unanimitat. ¿La tiara va ser comprada per Roderic de Borja amb simonia o aconseguida per altres motius?

Si observem les llistes dels tres escrutinis que ens han arribat, en el primer, els cardenals que van aconseguir més vots van ser els següents: Della Porta (5), Della Rovere (5), Piccolomini (6), Costa (7), Michiel (7), Borja (7) i Caraffa (9). En el segon, ens trobem amb el següent repartiment: Della Porta (5), Della Rovere (5), Costa (8), Michiel (7), Borja (8) i Caraffa (9). I finalment, en el tercer escrutini conservat: Della Rovere (6), Piccolomini (7), Costa (7), Michiel (10), Borja (8) i Caraffa (10) (La Torre 1933: 89-91).

Si observem com es van repartint els vots, veiem que arribem a una tercera votació que entra en un punt mort, en la qual el candidat oficial d'Ascanio Sforza, Oliveiro Caraffa, agafa la davantera amb 10 vots, empatat amb el cardenal Michiel.

¿Com és que en el quart i darrer escrutini va intervenir l'Esperit Sant per il luminar els cardenals que unànimement li van donar el seu vot al Borja? Com sempre, l'explicació més fàcil és la d'acusar aquest d'haver subornat els cardenals amb promeses de beneficis, càrrecs, propietats... 
Joan Emili Roig Matoses. Itàlia i la configuració de la llegenda negra borgiana.

L'orador Manfredo Manfredi, de Florència estant, informava irònicament la duquessa de Ferrara d'aquest fet:

Firenze... agosto 1492 - Illma et Exma Madama mia — Scrive lo Ambassatore del Magco Piero de' Medici como questo giorno, che è di xi ad hore xi, el fu creato Pontefice et publicato el Vice-Canzelleri, denominato Alexandro secto, et cum totale satisfactione del sacro Collegio de' Cardinali aprobato unitamente. Che, se così è, el non se ha ad credere, Illma Madama mia, considerato all pratiche che se erano facte, ch'el non sii creato veramente Spiritus Sancti, et tanto più quanto che de omni altro se stimava, salvo che de prelibato Vice-Canzelleri... (Capelli 1869: 26).

Manfredi, després d'aquesta irònica carta, n'escriu una altra, en data de 16 d'agost, on detalla les «donacions» fetes pel Borja als següents cardenals: Ascanio, Orsini, Riario, Colonna, Savelli, Sanseverino i Pallavicino. ¿La resta de cardenals no van obtenir cap prebenda? O, van renunciar a ella? O, ¿El Borja no va voler donar res a la resta de cardenals, tot i haver-los-en fet la promesa i, aquestos, resignadament i en pau, no van fer cap protesta pública? $\mathrm{O}$, ¿És que realment no va haver cap promesa per part del Borja per aconseguir el vot de tothom i el va aconseguir per altres motius? Més endavant explicarem perquè ens inclinem per aquesta darrera raó (Capelli 1869: 26-27).

En una altra carta, del 17 d'agost, escriu sobre l'absència d'unes teòriques quantitats de diners promesos en la repartició dels beneficis:

\footnotetext{
Perche nella comunicatione che ne fece el Magco Piero dello adviso havuto da Roma per la distributione delli offitii et benefitii che haveva facto el Papa non se conteneva quantità añchuna di denari che la havesse promessa a certi Cardinali (forsi per non volere sua Mag.tia esserne autore), et havendo dopoi io de buon luocho come lo havea dato Sua Santità, on promesso, el Cardinale Ursino,ultra li benfitii XXmilia dicati, al Collona XVmilia dicati, al Savello XXXmilia dicati, il mi è parso significarlo a V. Excell., acciochè la intenda che la practicha non se poteva tirare a questi Signori dove la conducta senza grande obligatione et promesse ; per il che è stato necessario ad devenire alli termini antedicti: chè quando el Collona, Savello et Orsino non havessero inclinato, la cosa portava periculo. La E. V. sapientissim, parendogli, tenerà in sè questo adviso della primissione delli denari (Capelli 1933: 27).
}

No neguem que totes aquestes donacions es van produir, i Roderic de Borja va haver de renunciar a tots els seus bisbats, a la casa seua, a rendes i a beneficis. Però volem assenyalar que va haver renunciar -terme ben diferent al de donar a canvi de-, tal i com era habitud i havien fet ja tots els papes anteriors.

Si repassem la història dels conclaves anteriors al de 1492, podrem veure amb uns altres ulls totes aquestes crítiques fetes al Borja, atés que hi havia en aquestes una clara intenció de voler demostrar 
Joan Emili Roig Matoses. Itàlia i la configuració de la llegenda negra borgiana.

que havia comprat el papat. Crítiques que no van rebre els anteriors pontífexs.

Ja a la mort de Calixt III, el 1458, el conclave que havia de nomenar un nou papa va començar amb dos candidats fortament oposats: Guglielmo d'Estouville, cardenal de Roano, i Enea Silvio Piccolomini. La lluita de poders entre els dos, i les promeses del magníficament ric cardenal francés, van marcar el seu desenvolupament. D'Estouville va arribar a prometre al cardenal d'Avinyó un arquebisbat, el seu palau de Roma i la vicecancelleria, si era elegit papa; a la resta de cardenals també els va prometre altres beneficis. Al final, però, Piccolomini va esdevenir papa Pius II, cosa que ens demostraria que intentar comprar els vots dels cardenals oferint-los grans beneficis no era garantia d'aconseguir-ne la tiara (La Torre 1933: 36).

En el conclave de 1484, en el qual Giovanni Battista Cibo va ser coronat com a papa Innocenci VIII, després de la reunió preceptiva per escollir-lo, també aquest va haver de fer el repartiment habitual que s'havia de fer, una vegada s'era escolit papa. I era, això, tan habitual, que només cal fixar-se en com pareix explicitat en un document que presentarem i que creiem que es clau per entendre aquest tipus d'episodis. En aquest sentit, convé veure com Infessura, al seu dietari, ens detalla la repartició d'aquests beneficis:

Deinde die sequenti detectum fuit, quod pro habendis vocibus multa bona Ecclesiae promiserit atque dederit, quorum aliqua hic scribuntur.

Primo, cardinilis Sabellus habuit castrum quod dicitur Monticelli in partibus Insulae; item legationem Bononiense.

Cardinalis Columnensis castrum Ceparani et legationem Patrimonii, et pro restauratione domus combustae et damnorum .xxv. millia ducatorum, et, ut dicitur, fuerunt ei promissa beneficia quam primum vacatu, quae fuit adempta camerario . item castrum Cerveteris.

Matisconensis castrum Capranicaeet spiscopatum Avinionensem.

Filio regis Ferdinandi fertur fuisse concemum Pontem Corvum. Item, data fuit ei domus, vel patatium, quod fuerat dicti papae dum erat cardinalis, videlicet Sancti Laurentii in Lucina.

Cardinalis Parmensis palatium Sancti loannis della Magliana una curn onmi eius aedificio.

Mediolanensi cardinali archipraesbyteratum Sancti loannis Lateranensis et legationem Avenionensem.

Cardinalis Sancti Petri ad Vincula et praefectus Urbis, eius frater, Fanum cum quinque aliis terris circumstantibus, promisitque facere dictum praefectum, eius fratrem, generalem capitanum Ecciestae.

Sed haec nunc ditta fuerunt, quae curn non fuerint reperta omnino vera, credendum est ea ditta fuisse propter invidiam et aemoulationem,potius quam pro veritate dicenda» (Infessura 1890: 171-172).

Vespuci, en una carta escrita en data de 29 d'agost de 1484, també ens dóna el repartiment realitzat i una dada molt interessant: Giuliano Della Rovere va renunciar a la part que li havia tocat, per repartir aquests beneficis entre altres cardenals que havien donat el seu vot al Cibo:

S. Piero in Vincula ha renunciato la Legatione di Bologna la quale fu data al Cardinale de Visconti, et lui la decta al Savello: et più ha renuntiato alla Legatione d'Avignone, et questa s'è 
Joan Emili Roig Matoses. Itàlia i la configuració de la llegenda negra borgiana.

data al Cardinale di Milano: la Legatione de Patrimonio havuta la Santità del Papa data a Parma, et lui la renuntio a monsignore de Visconti [...] Ila anchora S. Piero in Vincula renuntiato certe Badie, le quali no so come sieno distribute» (Burckard 1883, I: 516-517)

Però el document del que hem parlat abans i al qual ningú li ha volgut o sabut donar la importància que té, és el següent, que Burckard ens reporta al seu dietari, quan ens narra l'inici del conclave de 1884:

\footnotetext{
Ego N., electus in papam voveo, promitto et juro omnipotenti Deo et sanctis apostolis ejus Petro et Paulo et omnibus aliis sanctis, ac Ecclesie sancte Dei prefate, facere, attendere et observare et efficaciter adimplere omnia et singula infraseripta, scilicet

In primis de proventibus camem apostolice dare et solvere, seu dari et solvi facere centum florenos auri de camera omni mense cuilibet cardinali non habenti integre de proventibus ecclesiastieis et capitali quatuor millia florenorum annuatim, quousque ei provisum sit de dicta summa in redditibus, et cardinales omnes habentes quecumque beneficia ecclesiastica etiam incompatibilia in titulum vel in commendam manutenebo et defendam in possessione eorumdem. $[\ldots]$

Item, cum cardinales sancte romane ecclesie assidue assistant summo pontifici, et proinde debeant specialibus prerogativis et privilegiis gaudere, ex nunc concedo ipsis carditudibus plenariam el liberam dispositionem omnium et singulorum monasteriorum, prioratuum, dignitatum, personatuum, administrationum et ofticiorum, canonicatuum et prebendarum aliormuque beneficiorum ecelesiasticorum cum cura et sine cura, ad collationem, provisionem, presentationem, electionem, confirmationem... (Burckard 1883, I: 34-36).
}

Aquest document, que apareix sense cap nom a l'encapçalament, encara, és el compromís signat per tots els cardenals, just abans d'entrar al conclave, en el qual, aquell d'ells que fos elegit papa, prometia repartir tots els seus béns entre la resta de cardenals electors del conclave.

Per a nosaltres, aquest és un document clau per entendre com es desenvolupaven els conclaves, abans i després de l'elecció del pontífex. Ens demostra que els repartiments de les riqueses del papa electe eren un fet habitual i normal, tot i que no signifique necessàriament que això fora una pràctica ètica. De fet, creiem que aquest mateix document devia de ser signat tant en conclaves anteriors als de 1484 com en el de 1492. Per tant, que el papa repartira entre la resta de cardenals les seues possessions era un fet totalment acceptat per aquests i gens inusual com, passats els segles, s'ha volgut veure i presentar per part d'aquells qui han volgut tacar de simonia l'elecció d'Alexandre VI.

Com ja hem dit abans, segurament l'ascens del Borja a la càtedra de Sant Pere va ser un fet totalment imprevist. I això se'ns fa evident si observem, només, com es van produir les votacions dels tres escrutinis previs al de l'elecció, tot i ser un dels cardenals favorits pel nombre de vots rebuts durant les tres primeres votacions. En la quarta, alguna cosa va passar perquè tots els cardenals, fins i tot el màxim enemic d'Alexandre VI, Giuliano Della Rovere, donaren el seu vot al Borja i hi hagués fumata blanca. 
Joan Emili Roig Matoses. Itàlia i la configuració de la llegenda negra borgiana.

És la nit del 10 d'agost i, després de la tercera votació, les coses degueren començar a canviar. De fet, degueren produir-se converses $i$ acords fins a altes hores de la matinada, fins al punt que Ascanio Sforza va «facilitar» l'elecció del Borja, el dia següent.

¿Com és que Ascanio va deixar a un costat el seu candidat oficial, Oliveiro Caraffa? ¿Potser perquè el Borja l'havia comprat, tal i com diuen els informadors? No. Si haguera estat així, ¿Sforza hauria aconseguit el vot dels altres cardenals sense «non badare a espese»? És inqüestionable que el paper que va exercir aquella nit va ser decisiu perquè el Borja fos elegit però, no creiem que es decantés pel Borja per una qüestió de diners, ja que segurament disposava de més dels que el Borja li podia oferir, sinó per raons polítiques que intentarem detallar més endavant.

En data de 12 d'agost de 1492, Valori apunta que l'elecció del Borja ha estat totalment imprevista i no esperada per ningú. Veiem quin paper ha tingut Ascanio Sforza en ella: «Questa promotione è venuta fuori dell' expectatione di ogni persona, et mosign. Aschanio è stato quello che solo ha facto venire con arte non pichola il Pontificato in costui. quello che habbi inducto Aschanio non posso anchora intendere.» (Burckard 1883, II: 610).

En aquesta mateixa carta, Valori no entén encara per què Ascanio s'ha decantat pel Borja. Dos dies després, però, escriu el següent: «Altri giudicano che Ascanio non harebbe consentito questa elezione se non fussi ben certo di havere e continare nello stato.» (Burckard 1883, II: 612).

Segons Picotti, Ascanio sempre hauria tingut en ment el Borja com a futur papa, des del principi del conclave, i va mantenir Caraffa com a favorit per dissimular. Va ser després del tercer escrutini que Sforza va deixar veure quins eren els seus plans i va apostar clarament pel Borja, per raons d'estratègia política.

En la carta del 14 d'agost, Valori fa aquesta hipòtesi: «Questo suo desiderio del promovere el Vocecancelliere ha sempre ocultato, nè s'intense mai se non in Conclavi; et perchè a molti Cardinali pare essere stati offesi da Aschanio, non resta in questa Corte sanza qualche odio» (Burckard 1883, II: 612).

Ambrosio Mirabilia, en una carta escrita a Bartolomeo Calco el 13 d'agost, incideix també en el paper de Sforza en el resultat final de l'elecció:

\footnotetext{
Mons. Ascanio, quale è stato causa luy solo de farlo papa como sono certo la V. M. ne sia pienamente informatat et per tale cosa la Sua Ill. et Ra Sria ne ha acquistato tanto credito et reputatione ch'el non se potebre dire ne scrivere in modo che è reputato non solum il primo apresso alla Sua Sta, ma è reputato come papa (Von Pastor 1910: 536).
}

Aquests testimonis ens donen a entendre un argument que ja hem apuntat abans: l'elecció de Roderic de Borja com a papa va ser gràcies, en gran part, a Ascanio Sforza. Però, ¿Va ser feta 
Joan Emili Roig Matoses. Itàlia i la configuració de la llegenda negra borgiana.

perquè el Borja l'havia subornat? Nosaltres creiem que no. I no hi degué haver un acord simoníac entre Roderic de Borja i Ascanio Sforza per una sèrie de motius que passem a enunciar. En primer lloc, perquè, si observem el resultat dels tres escrutinis, el candidat oficial d'Ascanio, Caraffa, estava empatat a vots amb el cardenal Michiel i, segurament, ho hauria continuat estant en el següent escrutini, si no s'hagués decantat cap al Borja. En segon lloc, Roderic de Borja i Ascanio Sforza eren amics. En tercer lloc, Roderic de Borja era valencià, és a dir, no era francés, com Michiel, i els italians, l'última cosa que devien voler, era un papa francés que revifés el cisma d'Avinyó. Roderic de Borja era valencià, sí; però, feia 37 anys que vivia a Roma servint la Santa Seu i diferents papes, començant pel seu oncle Calixt III. No era italià, però tenia molts punts a favor i molts anys de servei en terres italianes. I, finalment, Roderic de Borja era el principal enemic de Giuliano Della Rovere, que estava aliat amb el rei de Nàpols, al remat, fent papa al Borja, Ascanio aconseguia una sonada derrota del bàndol napolità i, per tant, la victòria de Milà i del seu germà Il Moro. Era la gran victòria dels Sforza.

I llavors, Ascanio Sforza, la nit del 10 d'agost, que devia sospesar tots aquests arguments, va decidir abandonar l'opció del Caraffa i apostar pel Borja. Si va haver-hi simonia, no va ser entre Alexandre VI i Ascanio. La simonia va ser un instrument que aquest darrer va utilitzar per comprar els vots dels cardenals en favor del Borja.

D'aquesta manera, l'11 d'agost de 1492, Roderic de Borja era elevat al pontificat amb el nom d'Alexandre VI, gràcies a la totalitat dels vots del col legi cardenalici, menys un, el seu, que va anar destinat al cardenal de Nàpols, segons sabem per una carta de Niccolò Michelozzi, conseller del joveníssim cardenal de Medici, present en el conclave i, per tant, font primera del que allí dintre va passar.

Aquesta carta de Michelozzi té una importància tan gran que, al nostre parer, demostra la teoria que venim argumentant des del principi: la simonia no va marcar el conclave de 1492. Escriu Michelozzi a Piero de Medici el 12 d'agost:

\footnotetext{
Padrone mio. Uscimo hiermatina de conclavi con la elescione del pontefice, che intendeste, veramente magnifica et honorevole, la quale so che vi harà dato sommo piacere, come a noi altri. Habbiamo uno bello pontefice et apto a fare trionfare questa Corte ed a rendere a questa Sancta Sede la sua dignità. Diali Dio vita, secondo il bisogno de' christiani et nostro. El nostro monsignore se è portato da homo da bene et ha facto dire di sè in conclave et mostro di havere ingegno et animo. Era volto, come buona parte dalli altri, in principio ad altri che a questo, cioè e Napoli; et, quando vide quella cura desperata, anche lui si accomodò assai bene. Sonci mille minutie, che possono male scriversi, de' quali vi raguaglierò a boccha, che in pochi di spero essere ad camino per costi. In questo mezzo vi mando li squittini de' primi tre dì, in su che vi trastullerete un pezzo. L'ultimo, che fu hiermattina ex composito, fu tutto a un modo; solo el vicecancelliere, hora papa, dette il voto suo al reverendissimo cardinale de Napoli; et così fu fatto papa con grande unione et triumpho et fatte apresso tutte le altre cerimonie consuete et in cappella et in San Pietro, le quale non scrivo, perchè vi sono notissime [...] Le cose, che sono ite atorno, al mio parere impertinenti ad scrivere, intenderete da altri, insino che io vengha (Picotti 1929: 702-703).
} 
consuete et in cappella et in San Pietro, le quale non scrivo, perchè vi sono notissime [...] Le cose, che sono ite atorno, al mio parere impertinenti ad scrivere, intenderete da altri, insino che io vengha (Picotti 1929: 702-703).

El valor de la carta és incalculable. Michelozzi, com a conseller del cardenal de Medici, present en el conclave, va veure i escoltar el que allí passava i, per tant, aquestes paraules reflecteixen el que allí dintre va viure.

Per al conseller, aquesta elecció ha estat magnífica i honorable i el nou papa serà un autèntic servidor de la Santa Seu i del papat. En cap moment en què elogia el desenvolupament del conclave parla de simonia, ni de cap mercat simoníac entre els cardenals. Si Michelozzi hagués estat testimoni d'aquest mercadeig, el to de la carta i el contingut de la mateixa, estem segurs que hauria sigut molt diferent.

Només cap al final de la carta trobem una crítica, en una frase que podria malinterpretar-se, si no fem una acurada traducció: «Le cose, che sono ite atorno, al mio parere impertinenti ad scrivere, intenderete da altri, insino che io vengha.» No hem de caure en el parany de traduir «impertinenti» per «impertinent» sinó per «no pertinents» és a dir, el que Michelozzi ve a dir és que el que allí va passar, no és pertinent que t'ho escriga ja que te n'assabentaràs per altres.

Què és el que no és pertinent? La simonia? No, perquè no hauria tingut cap problema en denunciarla. El que el florentí no tenia ganes de contar, perquè sabia que altres ho farien -com així va ser-, no és cap altra cosa que el mateix espectacle ocorregut en els conclaves anteriors: el repartiment de beneficis, càrrecs, possessions, etc. Michelozzi es devia escandalitzar de l'espectacle donat pels cardenals, esperant les prebendes del Borja, el qual, no ho oblidem, estava obligat a repartir-les, com ja hem vist.

Finalment, i per acabar de refermar la nostra hipòtesi de com Roderic de Borja no va assolir la tiara papal mitjançant la simonia, volem reportar el següent fragment de Le Storie di suoi tempi de Sigismondo dei Conti, el qual considera que l'acord final de la quarta votació del conclave no es va produir per un acord simoníac, sinó perquè el Borja era el millor candidat i amb més experiència sobre la resta en els camps de la política, la diplomàcia, l'administració de la Santa Seu i la litúrgia eclesiàstica, Just el mateix que devia haver pensat l'Sforza:

E tanto numero elegerunt Rodericum Borgiam Valentinurn, Sanctae Romanae Ecclesiae virecancellarium, virum versatissimum, qui ingenio maximarum rerum usum addiderat, annos enim septem, et triginta in numero Cardinalium fuerat, a Calisto enim Tertio avunculo in eum ordinem admodum invenis adscitus, Senatui praeterea nunquam defuerat, nisi valetudine impeditus, et id quiderm perraro. Apud Pium, Paulum, Sixtum, et Innocentium Romanos Pontefices, sub quibus vixit, in pretio habitus fuerat, legationes in Hispaniis et Italia obierat, ceremoniarum scientia longe alios anteibat, actioque eius habebat et in voce summum splendorem, in motu summam dignitatem. Accedebat maiestas formae, quae etsi bonis animi posthabenda est, et in viro Christiano non magnopere requirenda videtur, tamen si adsit illaudanda non est, cum inaugustissimo quoque corpore plurimum sapientiae inesse soleat, et, 
Joan Emili Roig Matoses. Itàlia i la configuració de la llegenda negra borgiana.

\begin{abstract}
ut ait Summus Orator, persona Principis servire debeat oculis civium. Erat praeterea id aetatis, qua, ut Aristoteli placet, plurimum homenes sapiunt, annurn agens circiter sexagesimum; corpore autem inoffenso morbis qoud omnia numera Pontificia posset obire, nec imbecilitate sua vigorem animi frangeret, Quibus rebus factum est, ut omnium Collegarum dignus summu Pontificatu sit habitus (Dei Conti 1883: 53-54).
\end{abstract}

Aquest fragment no seria de relleu ni d'interés si no explicàrem que Dei Conti, a part de ser el secretari papal des de Sixt IV fins a Juli II, va ser molt amic i protegit de Giuliano Della Rovere, que se l'estimava tant que el va convertir en el seu secretari domèstic, quan arribà a ser papa Juli II. (Dei Conti 1883: 13-34).

Si ens hi fixem bé, un amic, servidor i partidari de Giuliano Della Rovere, el gran enemic d'Alexandre VI, es desfà en elogis al Borja i a les capacitats... i no fa aparéixer enlloc la simonia, cosa que ens fa veure clarament que ens trobem davant d'un document definitiu que desmunta amb força totes les acusacions simoníaques sobre del conclave de 1492 en el qual un segon valencià, un segon Borja, ocupà la càtedra de Sant Pere «ad mairoem Dei gloriam.» 
Joan Emili Roig Matoses. Itàlia i la configuració de la llegenda negra borgiana.

\section{Bibliografia}

Baronii, Caesaris (1880) Annales ecclesiastici, tomus vigesimus nonus 1454-1480, Barri-Ducis.

Bower, Archibald (1766) History of the popes from the foundation of see of Rome to the present time, 7 vols., London, Printed for the author, vol. 7.

Burckard, Johanes (1883) Diarium, sive Rerum urbanarum commentarii, 3 vols., Ed. L. Thuasne, Ernest Leroux Editeur, vols. 1-2.

Burckard, Johanes (2004) Dietari secret, València, Eliseu Climent Editor.

Capelli, Antonio (1869) Fra Girolamo Savonarola et notizie intorno il suo tempo, dintre de Atti e Memorie delle RR. Deputazioni di Storia patria per le provincie modenesi e parmesi, vol. IV, Modena, Carlo Vincenzi.

Dei Conti, Sigismondo (1883) Le Storie de's suoi tempi, dal 1475 al 1510, Roma, Tipografia di G. Barbera.

Gregorovius, Ferdinand (2007) Lucrècia Borja a partir de documents i epistolaris del seu temps, València, Tres i Quatre. Guicciardini, Francesco (1970) Storie fiorentini.Dialogo del reggimento di Firenze. Ricordi e altri scritti, a cura di E. Lugnani Scarano, Torino, UTET.

Guicciardini, Francesco (1970) Storia d'Italia, Torino, Einaudi.

Infessura, Stefano (1890) Diario della Città di Roma, Roma, Forzani e C. Tipografi del Senato.

La Torre, Ferdinando (1933) Del conclave di Alessandro VI Papa Borgia, Firenze-Ginevra-Roma, Leo S. Olschki Ed.

Luzio, Alessandro (1914) «Isabella d'Este e i Borgia», Arcbivo Storico Lombardo - Giornale della Società Storica Lombarda, Serie 5, fasc. 1-2.

Von Pastor, Ludwin (1910) The History of the popes, from the close of the middle ages, London: Kegan Paul, Trench, Trübner \& Co., LTD.

Picotti, Giovani Battista (1921) «Giovanni de' Medici nel conclave per l'elezione di Alessandro VI», Archivio della R. Società Romana di Storia Patria, vol. 44.

Picotti, Giovani Battista (1929) La Giovinezza di Leone X, Milano, Ulrico Hoepli Editore.

Porcari, Girolamo (1493) Commentarius de creatione et coronatione Alexandri VI, Roma, Euctarium Silber.

De Roo, Peter (1924) Material for a History of Pope Alexander VI, his relatives and his time, Bruges: Desclée de Brouwer and Co., 3 volums.

Sanchis i Sivera, Josep (1924) «El cardenal Rodrigo de Borja en Valencia», Boletín de la Real Academia de la Historia, tom 84, pp. 121-164.

Schüller Piroli, Susane (1990) Los Papas Borgia Calix to III y Alejandro VI, València, Edicions Alfons el Magmànim - IVEI. Scweitzer, Vinzenz (1909): «Zur Wahl Alexanders VI», Historisches Jabrbuch, 30, pp. 809-814.

Tommasini, Oreste (1883): La vita e gli scritti di Niccolò Machiavelli nella loro relą̧ione col machiavellismo, Roma: Ermanno Loescher. 